BMJ Open

Diabetes

Research

\& Care

\section{Adherence of self-monitoring of blood glucose in persons with type 1 diabetes in Sweden}

To cite: Moström $P$, Ahlén $E$, Imberg $\mathrm{H}$, et al. Adherence of self-monitoring of blood glucose in persons with type 1 diabetes in Sweden. BMJ Open Diabetes Research and Care 2017;5: 0000342. doi:10.1136/bmjdrc-2016000342

- Additional material is available. To view please visit the journal online (http://dx. doi.org/10.1136/bmjdrc2016-000342).

Received 16 October 2016 Revised 13 December 2016 Accepted 26 December 2016

This final article is available for use under the terms of the Creative Commons Attribution Non-Commercial 3.0 Licence; see http://drc.bmj.com

\section{(a) CrossMark}

For numbered affiliations see end of article.

Correspondence to Dr Marcus Lind; lind.marcus@telia.com

\section{ABSTRACT}

Objective: The primary aim was to evaluate the extent to which persons with type 1 diabetes perform selfmonitoring of blood glucose (SMBG) according to guidelines. Secondary objectives were to investigate predictors for good SMBG adherence, reasons for non-adherence, and association between SMBG frequency and hemoglobin A1C (HbA1C).

Methods: This was a survey-based cross-sectional study. Questionnaires were sent out to 600 random patients at five sites. Patients were included if they were diagnosed with type 1 diabetes and $\geq 18$ years old and excluded if they were currently using continuous glucose monitoring (CGM). Analysis of data was performed separately for the three sites where the answer frequency was $\geq 70 \%$.

Results: In total, 138 of 314 study participants, $43.9 \%$ (95\% Cl $38.5 \%$ to $49.4 \%$ ) performed SMBG $\geq 4$ times per day. For the three clinics where $\geq 70 \%$ of surveyed patients were included in the analysis, results were similar, $41.3 \%$ (95\% Cl $34.7 \%$ to $47.8 \%)$. Top three reported reasons for not performing more frequent SMBG were lack of time, not remembering, and self-consciousness. Frequency of SMBG was associated with $\mathrm{HbA1c}$ levels $(p<0.0001) .30 \%$ of patients believed that $\leq 3 \mathrm{SMBG} /$ day was recommended by healthcare providers.

Conclusions: Less than $50 \%$ of patients in Sweden follow guidelines of SMBG $\geq 4$ times per day, despite glucose meters and strips being generally available at no cost. This indicates a need for further support in performing SMBG and increased availability of other tools for glucose monitoring.

\section{BACKGROUND}

In persons with type 1 diabetes, obtaining good glycemic control is crucial in avoiding microvascular and macrovascular complications from the eyes, kidneys, nerves, and cardiovascular system, and reducing excess mortality. ${ }^{1-3}$ Simultaneously, it is important to minimize the risk of hypoglycemia, which leads to considerable discomfort and risk of serious complications for many patients. $^{2}$ Previous studies have shown a correlation between frequent self-monitoring of blood

\section{Significance of this study}

What is already known about this subject?

- Frequency of self-monitoring of blood glucose (SMBG) correlates with hemoglobin A1c and is considered an important factor for obtaining good glycemic control.

- Earlier studies on patients with diabetes type 1 have shown varying compliance to previous and current American Diabetes Association (ADA) guidelines, from two thirds of patients not performing daily SMBG, to $85 \%$ of patients measuring three times per day or more.

\section{What are the new findings?}

- Less than $50 \%$ of persons with type 1 diabetes in Sweden perform $S M B G \geq 4$ per day according to current ADA guidelines.

- $30 \%$ of patients are unaware of guidelines.

- The top two most reported reasons for not performing more frequent SMBG were 'not remembering' and 'lack of time'.

How might these results change the focus of research or clinical practice?

- Our results indicate a need for further supporting SMBG with repeated and focused information on current guidelines as well as continued development of user-friendly glucose-monitoring devices.

glucose (SMBG) and glycemic control measured by hemoglobin A1c (HbA1c). ${ }^{4-9}$ The difference in HbAlc between those not measuring their blood glucose at all and those measuring only a few times every week, but not daily, has been shown to be negligible. $^{5} 6$ In comparison, the difference between those never or seldom measuring and those measuring 3-4 times per day is about $1 \% \quad(10 \mathrm{mmol} / \mathrm{mol})$. The difference between measuring 3-4 times per day and measuring 10 times per day has also been shown to have an effect on HbAlc of about $1 \%(10 \mathrm{mmol} / \mathrm{mol})^{7}$

The American Diabetes Association's (ADA) Standards of Medical Care in 
Diabetes, suggest a partly individualized number of SMBG measurements per day for patients on intensive insulin regimes (multiple daily insulin injections or insulin pump). SMBG is recommended at least 4 times per day, but for many patients $6-10$ times per day is appropriate to achieve good metabolic control. ${ }^{10} 11$ Earlier studies on patients with diabetes type 1 have shown varying adherence to guidelines, from two-thirds of patients not performing daily $\mathrm{SMBG},{ }^{6}$ to $85 \%$ of patients measuring 3 times per day or more. ${ }^{7}$ Some studies are limited to patients downloading blood glucose meter data at the clinic, probably leaving out a large proportion of non-adherent patients. Many modern studies are focused on continuous glucose monitoring (CGM); however, a vast majority of patients are limited to traditional blood glucose meters because of limited reimbursement of CGM. Therefore, more recent data on patient adherence to modern guidelines using traditional blood glucose meters is weak, especially in Sweden, where no such study has been conducted.

The aim of the present study was to describe the proportion of patients measuring blood glucose levels at least 4 times per day. Secondary objectives were to further investigate possible predictors for good SMBG adherence as well as studying the association between SMBG frequency and HbA1c.

\section{METHODS}

\section{Study design}

This study was designed as a cross-sectional observational study with retrospective elements and performed 20132014. The study protocol and questionnaire were approved by the regional ethical committee in Gothenburg, Sweden. A questionnaire was sent to the patients, and answers to the questionnaire were matched with record data corresponding to each patient from local databases. Patients gave written informed consent together with the questionnaire.

\section{Study subjects}

Study patients were recruited from five different hospital outpatient clinics (Alingsås Lasarett, Kungälvs Sjukhus, Södra Älvsborgs Sjukhus/Borås, Uddevalla Sjukhus, and Sahlgrenska University Hospital/Östra Sjukhuset in Västra Götaland, Sweden). A random subset of patients was selected at each clinic from a list of all patients attending that clinic. Inclusion criteria were diabetes mellitus type 1 and age $\geq 18$ years. Exclusion criteria was usage of CGM.

\section{Questionnaire}

A translated version of the questionnaire that patients received is included in the supplement. The first part of the questionnaire included questions on habits of SMBG based on glucose meter data and estimation. Patients were required to check their blood glucose meters and count the number of measurements in the previous 7 and 30 days. The mean number of measurements per day was calculated by dividing the total number of measurements by the number of days. The second part included comorbidity questions and baseline data such as social demographics, physical activity level (altered Saltin-Grimby scale), alcohol habits, smoking habits, diabetes duration, use of carbohydrate counting, type of insulin delivery, known macrovascular and microvascular complications, and stress level.

The questionnaire also included questions about perceived recommendations of SMBG and attitudes towards SMBG. Data presented in this paper were based on the following questions from the questionnaire:

- How many times have you measured your blood glucose in the past week?

- How many times have you measured the blood glucose in the last 30 days?

- How often should you measure your blood glucose levels under optimal conditions according to your clinic? (per day)

- What is/are the main reason/reasons for not performing more frequent measurements?

- What could make you perform more frequent measurements?

Patients received questionnaires by mail. If no response was received, a second questionnaire was mailed as a reminder. If there was no response to the second questionnaire, patients were contacted by telephone. A final attempt was made at clinical visits for patients who had not been reached or if there was no response to the second questionnaire.

\section{Registry data}

Data from patients completing the questionnaire was obtained from the Swedish National Diabetes Registry (NDR) and local record databases. The two most recent HbAlc values prior to completing the questionnaire were obtained and mean value of these two were used in analysis. Additional data retrieved from the NDR were the most recent known body mass index (BMI) and albuminurea status. HbAlc was measured using routine methods at each center. All local laboratories participate in a nationwide standardization program that compares laboratory methods with a nationwide reference, a program called EQUALIS (External quality assessment for clinical laboratory investigations). In Sweden, HbAlc levels are typically reported using the International Federation of Clinical Chemistry system $(\mathrm{mmol} / \mathrm{mol})$. Values were converted to the National Glycohemoglobin Standardization Program system $(\%)$ and are also presented here.

\section{Statistical analysis}

In total, 600 patients were asked to participate in the study. A 30\% loss rate was assumed, giving a total of 420 patients. With this sample size, a 95\% CI for the proportion of patients with type 1 diabetes measuring blood glucose four or more times daily gives a width of 9.4 percentage units at most. 
A statistical analysis plan was created before the database was locked. Before any data analysis was performed, the response rate was controlled, and was greater at three sites. Therefore, separate analyses were performed for these sites and the complete sample.

For descriptive purposes, data are presented as mean (SD), median, and minimum and maximum values for continuous variables. Categorical variables are presented as numbers with percentages. The proportion of patients with SMBG values above or below certain thresholds is shown with $95 \%$ CIs using normal approximation.

For group comparisons, the Mann-Whitney $\mathrm{U}$ test was used for continuous variables, Mantel-Haenszel $\chi^{2}$ test for ordered categorical variables, Pearson $\chi^{2}$ test for non-ordered categorical variables, and Fishers exact test for dichotomous variables. For analyses between two ordinal or continuous non-normal continuous variables, Spearman rank correlation was used.

Analysis of SMBG in relation to patient characteristics was performed using linear regression, with stepwise selection to find the most important predictors of SMBG. Regression modeling was also used to describe HbA1c as a function of SMBG. Various model structures, such as linear, quadratic, and piecewise linear, were investigated and compared in terms of Akaike's Information Criterion, and the best one was used in the analyses.

As patients are clustered within clinics, sensitivity analyses accounting for possible within-clinic correlation were performed. For binary outcomes, this was done with SAS proc genmod, fitting a logistic regression model using generalized estimating equations (GEE) with compound symmetric correlation structure within clinic. For continuous outcomes, this was done with SAS proc mixed, using a covariance pattern model with compound symmetric correlation structure within clinic.

All tests were performed at the 5\% significance level. All analyses were conducted using SAS V.9.4 (Cary, North Carolina, USA).

\section{RESULTS}

\section{Baseline characteristics}

Of 600 patients, 29 were excluded for CGM use, leaving a total of 571 patients. Of these, $333(58 \%)$ agreed to participate. At the three clinics with the highest frequency of patients responding, the response rate was $\geq 70 \%$. Four patients were excluded for apparently misunderstanding the questionnaire, leaving 329 patients in the study, and a $95 \%$ CI for the proportion with a width of at most 10.8 percentage units. Data are presented separately from the three clinics with the highest answer frequency. Table 1 presents demographics, baseline characteristics, and medical and surgical history. When clinics with high response rates were compared with clinics with lower response rates, a significant difference was noted in level of education, residential status, physical activity, BMI, carbohydrate counting, and HbA1c. In the two samples with higher and lower response rates, mean $\mathrm{HbAlc}(\mathrm{mmol} / \mathrm{mol})$ values were 62.6 and 59.5 $(\mathrm{p}=0.042)$, BMI values were 25.9 and $24.8 \mathrm{~kg} / \mathrm{m}^{2}$ $(\mathrm{p}=0.023)$, and mean ages were 48.0 and 44.3 years $(\mathrm{p}=0.052)$, respectively.

\section{SIMBG according to guidelines}

The proportion of subjects with $\mathrm{SMBG} \geq 4$ daily in the last 30 days was $43.9 \%$ ( $\mathrm{n}=138$ of $314,95 \%$ CI $38.5 \%$ to $49.4 \%)$. For the three clinics with highest response rate, $41.3 \%$ performed $\geq 4$ SMBG/day $(n=90$ of $218,95 \%$ CI $34.7 \%$ to $47.8 \%$ ) (table 2). SMBG for individuals within the same clinics were essentially independent $(r<0.05)$ and a sensitivity analysis accounting for within-clinic correlation gave similar results to those presented in table 2 (data not shown). The distribution of SMBG frequency is shown for each group in figure 1A.

The median patient belief was that recommended number of daily SMBG was $4.29 .7 \%$ of patients believed that $\leq 3$ SMBG measurements per day were recommended by healthcare providers, and $11.4 \%$ believed that $\leq 2$ SMBG measurements were recommended (see online table S2 supplement). Postprandial measurements were seldom performed; the median number per week was 4 in both groups.

The number of SMBG measurements performed during the last 30 days correlated with patient perceptions of the mean number of measurements performed per day, $\mathrm{r}=0.89(\mathrm{p}<0.0001)$ in all clinics. Patient apprehension of the recommended number of SMBG measurements showed a weaker yet statistically significant correlation to the actual number of measurements, $\mathrm{r}=0.42, \mathrm{p}<0.0001$.

Using data from all clinics, predictors for performing more frequent SMBG were older age $(p=0.033)$ and female sex $(p<0.001)$, using multiple regression analysis $\left(\mathrm{R}^{2}: 3.6 \%\right)$. In univariate analyses, residential status (living single with children) and high physical activity showed a significant association with SMBG frequency ( $p=0.046$ and $p=0.049$, respectively). The association with high stress level was of borderline significance $(p=0.055)$. When using the same methodology for the three clinics where response rate was $\geq 70 \%$, age was the only significant predictor $(\mathrm{p}=0.004)$. Results are shown in table 3. When using a model that accounted for dependencies within clinics, a non-significant intraclinic correlation was seen and similar results in the analysis of predictors of more frequent SMBG were obtained (data not shown).

\section{SIMBG barriers and possible support}

Using data available from all clinics, 176 answers for the question 'Reasons for not performing more frequent SMBG' were obtained. 'Lack of time' and 'Not remembering' were the most frequent reported reasons for not performing more frequent measurements, $\mathrm{n}=89(51 \%)$ and $\mathrm{n}=94$ (53\%), respectively. 
Table 1 Demographics and baseline characteristics

\begin{tabular}{|c|c|c|c|c|}
\hline & $\begin{array}{l}\text { All sites } \\
(n=329)\end{array}$ & $\begin{array}{l}\text { Site } 1-3 \\
(n=228)\end{array}$ & $\begin{array}{l}\text { Site 4-5 } \\
(n=101)\end{array}$ & p-Value \\
\hline \multirow[t]{3}{*}{ Age (years) } & $46.9(16.7)$ & $48.0(16.6)$ & $44.3(16.5)$ & 0.052 \\
\hline & $47.0(18.0 ; 87.0)$ & $48.0(18.0 ; 87.0)$ & $44.0(18.0 ; 83.0)$ & \\
\hline & $n=328$ & $n=227$ & $\mathrm{n}=101$ & \\
\hline Female & $145(44.2 \%)$ & $99(43.6 \%)$ & $46(45.5 \%)$ & 0.84 \\
\hline \multirow[t]{3}{*}{ Diabetes duration (years) } & $21.8(15.1)$ & $22.6(15.3)$ & $20.1(14.5)$ & 0.19 \\
\hline & $19.0(0.0 ; 62.0)$ & $20.0(0.0 ; 62.0)$ & $17.0(0.0 ; 61.0)$ & \\
\hline & $n=329$ & $\mathrm{n}=228$ & $\mathrm{n}=101$ & \\
\hline \multicolumn{5}{|l|}{ Smoking } \\
\hline Never smoked & $173(56.5 \%)$ & $114(55.3 \%)$ & $59(59.0 \%)$ & \\
\hline Regular smoker & $20(6.5 \%)$ & $15(7.3 \%)$ & $5(5.0 \%)$ & \\
\hline Occasional smoker & $34(11.1 \%)$ & $21(10.2 \%)$ & $13(13.0 \%)$ & \\
\hline Previous smoker & $79(25.8 \%)$ & $56(27.2 \%)$ & $23(23.0 \%)$ & 0.56 \\
\hline \multicolumn{5}{|l|}{ Level of education } \\
\hline Unfinished primary school & $6(2.0 \%)$ & $5(2.5 \%)$ & $1(1.0 \%)$ & \\
\hline Finished primary school & $33(10.9 \%)$ & $22(10.9 \%)$ & $11(10.9 \%)$ & \\
\hline High school & $184(60.7 \%)$ & $132(65.3 \%)$ & $52(51.5 \%)$ & \\
\hline College/University degree & $80(26.4 \%)$ & $43(21.3 \%)$ & $37(36.6 \%)$ & 0.023 \\
\hline \multicolumn{5}{|l|}{ Occupation } \\
\hline Working & $189(62.0 \%)$ & $126(61.8 \%)$ & $63(62.4 \%)$ & \\
\hline Student & $19(6.2 \%)$ & $8(3.9 \%)$ & $11(10.9 \%)$ & \\
\hline Retired & $64(21.0 \%)$ & $48(23.5 \%)$ & $16(15.8 \%)$ & \\
\hline Unemployed & $14(4.6 \%)$ & $9(4.4 \%)$ & $5(5.0 \%)$ & \\
\hline Sick-leave/Disability pension & $19(6.2 \%)$ & $13(6.4 \%)$ & $6(5.9 \%)$ & 0.12 \\
\hline \multicolumn{5}{|l|}{ Residential status } \\
\hline Married/cohabitant, without children & $115(37.6 \%)$ & $88(42.9 \%)$ & $27(26.7 \%)$ & \\
\hline Married/cohabitant, with children & $84(27.5 \%)$ & $54(26.3 \%)$ & $30(29.7 \%)$ & \\
\hline Living with children without other adult(s) & $18(5.9 \%)$ & $12(5.9 \%)$ & $6(5.9 \%)$ & \\
\hline Living with other person (not any of above) & $33(10.8 \%)$ & $21(10.2 \%)$ & $12(11.9 \%)$ & \\
\hline Living alone & $56(18.3 \%)$ & $30(14.6 \%)$ & $26(25.7 \%)$ & 0.045 \\
\hline \multicolumn{5}{|l|}{ Stress level } \\
\hline Never experienced stress & $24(7.8 \%)$ & $19(9.2 \%)$ & $5(5.0 \%)$ & \\
\hline Have experienced some period with stress & $96(31.4 \%)$ & $62(30.1 \%)$ & $34(34.0 \%)$ & \\
\hline Some period with stress last 5 years & $113(36.9 \%)$ & $79(38.3 \%)$ & $34(34.0 \%)$ & \\
\hline Constant stress last year & $36(11.8 \%)$ & $23(11.2 \%)$ & $13(13.0 \%)$ & \\
\hline Constant stress last 5 years & $37(12.1 \%)$ & $23(11.2 \%)$ & $14(14.0 \%)$ & 0.37 \\
\hline \multicolumn{5}{|l|}{ Physical activity } \\
\hline Little & $27(9.0 \%)$ & $18(8.9 \%)$ & $9(9.2 \%)$ & \\
\hline Moderate & $122(40.7 \%)$ & $94(46.5 \%)$ & $28(28.6 \%)$ & \\
\hline Moderate and regular & $79(26.3 \%)$ & $53(26.2 \%)$ & $26(26.5 \%)$ & \\
\hline Regular exercise & $72(24.0 \%)$ & $37(18.3 \%)$ & $35(35.7 \%)$ & 0.0027 \\
\hline \multirow[t]{3}{*}{$\mathrm{HbA} 1 \mathrm{c}(\mathrm{mmol} / \mathrm{mol})$} & $61.7(12.7)$ & $62.6(12.7)$ & $59.5(12.4)$ & 0.042 \\
\hline & $60.5(35.0 ; 119.0)$ & $61.5(35.0 ; 119.0)$ & $59.0(35.0 ; 92.0)$ & \\
\hline & $n=328$ & $n=227$ & $n=101$ & \\
\hline \multirow[t]{3}{*}{ BMI } & $25.5(4.0)$ & $25.9(4.2)$ & $24.8(3.5)$ & 0.023 \\
\hline & $25.0(18.0 ; 41.0)$ & $25.5(18.0 ; 41.0)$ & $24.0(19.0 ; 40.0)$ & \\
\hline & $\mathrm{n}=327$ & $n=226$ & $\mathrm{n}=101$ & \\
\hline Uses carbonate counting & $105(35.1 \%)$ & $58(29.0 \%)$ & 47 (47.5\%) & 0.0027 \\
\hline \multicolumn{5}{|l|}{ Insulin delivery } \\
\hline MDI & $247(75.3 \%)$ & $166(73.1 \%)$ & $81(80.2 \%)$ & \\
\hline Insulin pump & $81(24.7 \%)$ & $61(26.9 \%)$ & $20(19.8 \%)$ & 0.22 \\
\hline \multicolumn{5}{|l|}{ Medical and surgical history } \\
\hline Laser treatment & $66(20.1 \%)$ & $45(19.7 \%)$ & $21(20.8 \%)$ & 0.93 \\
\hline Microalbuminuria & $14(4.3 \%)$ & $7(3.1 \%)$ & $7(6.9 \%)$ & 0.20 \\
\hline Foot ulcer & $16(4.9 \%)$ & $9(3.9 \%)$ & $7(6.9 \%)$ & 0.37 \\
\hline Stroke & $12(3.6 \%)$ & $7(3.1 \%)$ & $5(5.0 \%)$ & 0.58 \\
\hline Myocardial infarction & $8(2.4 \%)$ & $4(1.8 \%)$ & $4(4.0 \%)$ & 0.41 \\
\hline Percutaneous coronary intervention & $11(3.9 \%)$ & $7(3.8 \%)$ & $4(4.0 \%)$ & 1.00 \\
\hline Aorto-coronary bypass surgery & $7(2.5 \%)$ & $5(2.7 \%)$ & $2(2.0 \%)$ & 1.00 \\
\hline
\end{tabular}

For categorical variables $\mathrm{n}(\%)$ is presented.

For continuous variables Mean (SD) / Median (Min; Max) / $n=$ is presented.

Comparison of demographics and baseline characteristics is made for the three sites with $\geq 70 \%$ response rate versus the two sites with $<70 \%$ response rate using Fisher's Exact test for dichotomous variables, Mantel-Haenszel Chi Square test for ordered categorical variables, Pearson Chi Square test for non-ordered categorical variables and the Mann-Whitney U-test for continuous variables.

$\mathrm{BMI}$, body mass index; HbA1c, hemoglobin A1c; MDI, multiple daily injections. 
Table 2 Primary Analysis: Self-Monitoring of Blood Glucose.

\begin{tabular}{|c|c|c|}
\hline & $\begin{array}{l}\text { Site 1-3 } \\
(n=228)\end{array}$ & $\begin{array}{l}\text { All sites } \\
(n=329)\end{array}$ \\
\hline $\begin{array}{l}\text { Responders on SMBG last } 30 \text { days } \\
\text { SMBG >= } 4 \text { last } 30 \text { days }\end{array}$ & $\begin{array}{l}n=218 \\
90(41.3 \%) \\
(34.7 \% \text { to } 47.8 \%)\end{array}$ & $\begin{array}{l}n=314 \\
138(43.9 \%) \\
(38.5 \% \text { to } 49.4 \%)\end{array}$ \\
\hline SMBG $>=3$ last 30 days & $\begin{array}{l}124(56.9 \%) \\
(50.3 \% \text { to } 63.5 \%)\end{array}$ & $\begin{array}{l}184(58.6 \%) \\
(53.2 \% \text { to } 64.0 \%)\end{array}$ \\
\hline SMBG $<=1$ last 30 days & $\begin{array}{l}42(19.3 \%) \\
(14.0 \% \text { to } 24.5 \%)\end{array}$ & $\begin{array}{l}56(17.8 \%) \\
(13.6 \% \text { to } 22.1 \%)\end{array}$ \\
\hline $\begin{array}{l}\text { Responders on SMBG last } 7 \text { days } \\
\text { SMBG >= } 4 \text { last } 7 \text { days }\end{array}$ & $\begin{array}{l}n=223 \\
93(41.7 \%) \\
(35.2 \% \text { to } 48.2 \%)\end{array}$ & $\begin{array}{l}n=323 \\
147(45.5 \%) \\
(40.1 \% \text { to } 50.9 \%)\end{array}$ \\
\hline SMBG $>=3$ last 7 days & $\begin{array}{l}138(61.9 \%) \\
(55.5 \% \text { to } 68.3 \%)\end{array}$ & $\begin{array}{l}202(62.5 \%) \\
(57.3 \% \text { to } 67.8 \%)\end{array}$ \\
\hline SMBG $<=1$ last 7 days & $\begin{array}{l}35(15.7 \%) \\
(10.9 \% \text { to } 20.5 \%)\end{array}$ & $\begin{array}{l}47(14.6 \%) \\
(10.7 \% \text { to } 18.4 \%)\end{array}$ \\
\hline Number of daily SMBG last 30 days & $\begin{array}{l}3.5(2.4) \\
3.2(0.0 ; 14.7) \\
n=218\end{array}$ & $\begin{array}{l}3.7(2.7) \\
3.3(0.0 ; 14.7) \\
n=314\end{array}$ \\
\hline Number of daily SMBG last 7 days & $\begin{array}{l}3.6(2.2) \\
3.6(0.0 ; 10.6) \\
n=223\end{array}$ & $\begin{array}{l}3.9(2.5) \\
3.6(0.0 ; 12.9) \\
n=323\end{array}$ \\
\hline Number of SMBG per day as estimated by study persons & $\begin{array}{l}3.9(2.6) \\
4(0 ; 25) \\
n=207\end{array}$ & $\begin{array}{l}4.2(2.7) \\
4(0 ; 25) \\
n=307\end{array}$ \\
\hline How many SMBG per day do you think is recommended? & $\begin{array}{l}3.9(1.1) \\
4(1 ; 5) \\
n=171\end{array}$ & $\begin{array}{l}3.9(1.1) \\
4(1 ; 5) \\
n=246\end{array}$ \\
\hline Number of postprandial measurements per week & $\begin{array}{l}6.3(7.7) \\
4(0 ; 35) \\
n=195\end{array}$ & $\begin{array}{l}7.3(8.9) \\
4(0 ; 50) \\
n=290\end{array}$ \\
\hline Number of complete blood sugar curves per month & $\begin{array}{l}2.3(6.8) \\
0.0(0 ; 31) \\
n=190\end{array}$ & $\begin{array}{l}3.2(8.2) \\
0(0 ; 31) \\
n=275\end{array}$ \\
\hline
\end{tabular}

Results are presented for the sites with $\geq 70 \%$ response rate separately and for all five sites.

For categorical variables, $\mathrm{n}(\%) / 95 \% \mathrm{Cl}$ for proportion is presented. Confidence intervals are computed using normal approximation. Mean (SD) / median ( $\min ; \max$ ) / $\mathrm{n}=$ is presented for continuous variables.

$\mathrm{SMBG}$, self-monitoring of blood glucose.

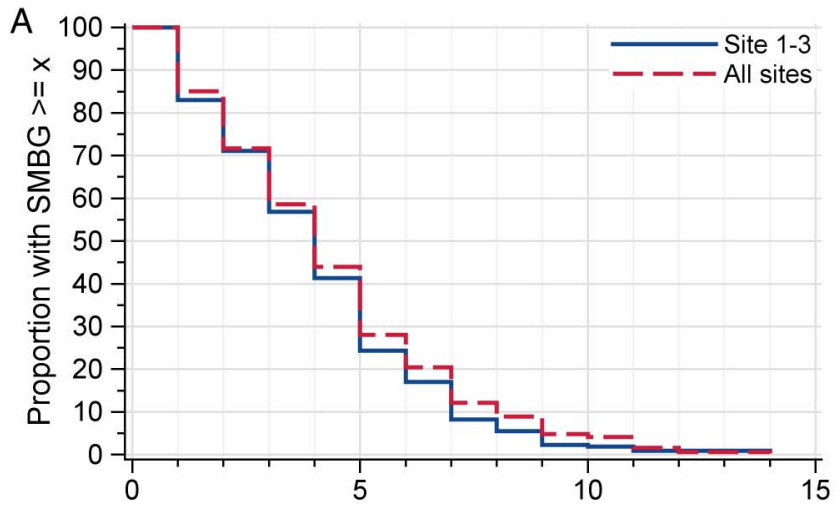

Number of daily SMBG last 30 days

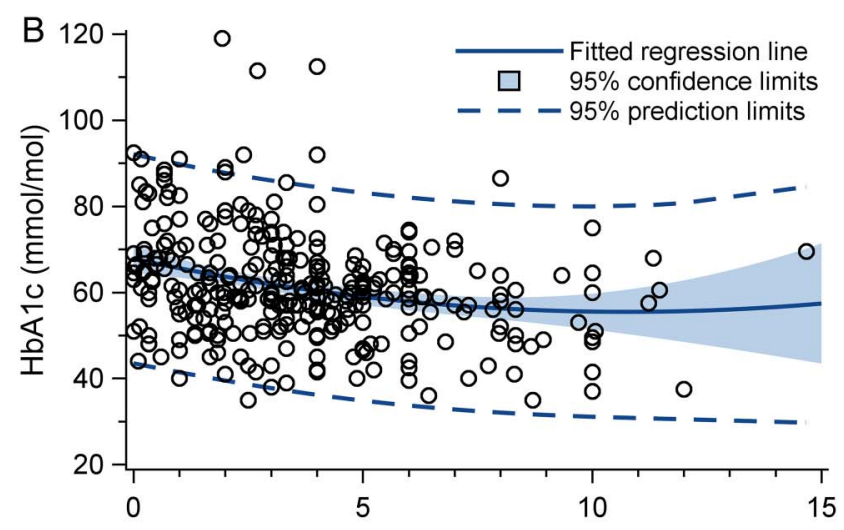

Number of daily SMBG last 30 days

Figure 1 (A) Distribution of number of daily SMBG last 30 days. (B) HbA1c as function of daily SMBG. HbA1c, hemoglobin A1c; SMBG, self-monitoring of blood glucose. 
Table 3 Average daily SMBG last 30 days related to patient characteristics (all sites)

\begin{tabular}{|c|c|c|c|c|}
\hline \multirow[b]{2}{*}{ Variable } & \multicolumn{2}{|l|}{ Univariable* } & \multicolumn{2}{|l|}{ Multivariable } \\
\hline & Beta (95\% Cl) & p-Value & Beta (95\% Cl) & p-Value \\
\hline Age (per 5 years) & $0.10(0.01$ to 0.19$)$ & 0.029 & $0.10(0.01$ to 0.18$)$ & 0.033 \\
\hline Female sex & $0.80(0.21$ to 1.39$)$ & 0.0084 & $0.78(0.19$ to 1.37$)$ & 0.0097 \\
\hline Diabetes duration (per 5 years) & $-0.00(-0.10$ to 0.10$)$ & 0.99 & & \\
\hline Smoker & $-0.17(-0.97$ to 0.63$)$ & 0.68 & & \\
\hline High school or higher & $0.09(-0.82$ to 0.99$)$ & 0.85 & & \\
\hline \multicolumn{5}{|l|}{ Occupation } \\
\hline Working/Student & $-0.53(-1.18$ to 0.12$)$ & 0.11 & & \\
\hline Retired & $0.54(-0.20$ to 1.27$)$ & 0.15 & & \\
\hline Unemployed/Sick-leave/Disability pension & $0.26(-0.72$ to 1.25$)$ & 0.60 & & \\
\hline \multicolumn{5}{|l|}{ Residential status } \\
\hline Living with other adult(s) & $0.56(-0.15$ to 1.27$)$ & 0.12 & & \\
\hline Single with children & $-1.31(-2.60$ to -0.02$)$ & 0.046 & & \\
\hline Living alone & $-0.20(-0.99$ to 0.60$)$ & 0.63 & & \\
\hline Stress level (1-5) & $0.27(-0.01$ to 0.55$)$ & 0.059 & & \\
\hline Physical activity (1-4) & $0.32(0.00$ to 0.64$)$ & 0.049 & & \\
\hline BMI (per 5 units) & $0.00(-0.37$ to 0.37$)$ & 0.99 & & \\
\hline Insulin pump & $0.12(-0.58$ to 0.82$)$ & 0.73 & & \\
\hline Carbohydrate counting & $0.34(-0.31$ to 0.98$)$ & 0.31 & & \\
\hline Laser treatment & $-0.11(-0.85$ to 0.62$)$ & 0.76 & & \\
\hline Microalbuminuria & $0.07(-1.47$ to 1.62$)$ & 0.93 & & \\
\hline Foot ulcer & $-0.77(-2.12$ to 0.57$)$ & 0.26 & & \\
\hline Stroke & $0.47(-1.07$ to 2.02$)$ & 0.55 & & \\
\hline Myocardial infaction & $0.49(-1.38$ to 2.37$)$ & 0.61 & & \\
\hline Percutaneous coronary intervention & $-0.31(-1.90$ to 1.27$)$ & 0.70 & & \\
\hline Aorto-coronary bypass surgery & $0.11(-1.87$ to 2.08$)$ & 0.92 & & \\
\hline
\end{tabular}

These two reasons were associated with lower age $(\mathrm{p}<0.0001)$, shorter diabetes duration $(\mathrm{p}=0.032)$, higher education $\quad(\mathrm{p}=0.003)$, and full-time occupation $(\mathrm{p}<0.0001)$. In addition, 'Not remembering' was associated with higher HbAlc $(\mathrm{p}<0.001)$, higher insulin dose $(\mathrm{p}=0.003)$, and fewer SMBG $(\mathrm{p}=0.003)$.

'Self-consciousness' was reported by $37(21 \%)$ patients and 'Pain/discomfort from the measurement itself' by $24(14 \%)$. A total of 10 patients $(6 \%)$ reported 'Not wanting to know' as a main reason.

Using data available from all clinics, 278 answers for the question 'What could make you perform SMBG more often?' were obtained. 'Other reason(s)' and 'Nothing' were the most frequent reported reasons, $\mathrm{n}=95(34 \%)$ and $\mathrm{n}=97(35 \%)$, respectively. 'Smaller and more user-friendly tools' were reported by $68(25 \%)$ patients and 'IT tools' by $25(21 \%)$.

The corresponding figures are presented for the clinics with highest and lowest response rate separately in online table S4 in Supplement.

\section{Hemoglobin A1c and self-monitoring of blood glucose}

Using data from all clinics, more frequent SMBG measurements were associated with lower HbA1c $(\mathrm{p}<0.0001$, $\mathrm{R} 2=6.8 \%$ ), analyzed with quadratic regression and adjusted for potential confounders. Adjustments were made for smoking, physical activity, and type of insulin delivery, which all showed associations with HbAlc in univariate analyses. Compared to no monitoring, one SMBG/day was associated with a $2.4 \mathrm{mmol} / \mathrm{mol}$, or $0.2 \%$, lower $\mathrm{HbAlc}$ level, which increased monotonically to a $7.9 \mathrm{mmol} / \mathrm{mol}$, or $0.8 \%$, reduction in HbAlc at 4 measurements.

Crude and adjusted reductions in HbAlc per unit change in SMBG are shown in online table S3 in the Supplement. No significant changes in HbA1c were seen for daily SMBG measurements greater than 7. Overall, HbA1c changed significantly with SMBG in unadjusted $(\mathrm{p}<0.0001)$ and adjusted models $(\mathrm{p}<0.0001)$. Analyses of SMBG in relation to HbAlc showed similar results when data were analyzed from the three clinics with highest response rate and when accounting for possible intraclinic correlation (data not shown).

\section{DISCUSSION}

To the best of our knowledge, this is the first study evaluating the proportion of persons with type 1 diabetes performing SMBG according to current guidelines of four times per day or more. A minority of patients (41\%) fulfilled this criterion. Further, it shows that $30 \%$ of patients believed that fewer than $4 \mathrm{SMBG} /$ day were recommended, and $11 \%$ believed that as few as $\leq 2$ measurements/day were recommended. HbAlc was 
associated with frequency of SMBG measurements, but SMBG explained only a relatively small part of the HbA1c level. Older age and female sex were associated with more frequent SMBG than younger age and male sex.

Karter et al showed that $34 \%$ of persons with type 1 diabetes performed SMBG 3 times or more per day. Data were based on sales of test strips, an in-direct measure of SMBG. The study was performed at a single health maintenance organization (Kaiser Permanente). In a study by Miller et al, ${ }^{7} 93 \%$ of persons with type 1 diabetes selfreported performing SMBG three or more times per day, and $62 \%$ did so five or more times per day. This study included children, while a slightly lower testing frequency was seen in adults. Others ${ }^{12}$ have studied adherence to SMBG recommendations but did not report the actual frequency of SMBG measurements per day.

Several observational studies have shown an association between frequency of SMBG and HbA1c. ${ }^{4-9}$ The extent to which the number of SMBG measurements explains HbAlc level in the present study is relatively low, although there was a statistically significant association $(p<0.0001)$. Adjusted R-square for SMBG measurements during the last 30 days and HbAlc level at all clinics was $6.8 \%$. This indicates that the number of SMBG measurements was estimated to explain around $7 \%$ of the HbAlc level, while other factors explain the remaining 93\%. Therefore, other factors are likely crucial for obtaining good glycemic control. Hence, although a present focus is on the development of novel glucose monitoring systems such as CGM and Flash Glucose Monitoring, it is still important for clinicians to focus on other tools such as dietary advice, psychological interventions in certain patients, and insulin adjustments. $^{14-17}$

The correlation between HbA1c and SMBG may have been weakened by the fact that HbA1c was not measured using a standardized chronological distance to the questionnaire being fulfilled, but rather the mean of the two latest known values. However, this approach was chosen due to the apparent risk that patients more often measure blood glucose closer to clinic visits, thus leading to falsely higher results in the primary analysis of SMBG frequency. It is possible that lack of power may explain the lack of a significant association between HbA1c and SMBG measurements $>7$. A limitation to this study was that the devices used by patients were not calibrated nor of the same model. Differences in accuracy could theoretically affect HbAlc independently. ${ }^{18}{ }^{19}$ However, public procurements in Sweden only allow blood glucose meters with a $\mathrm{CV}$ of $<10 \%,{ }^{20}$ which ensures a relatively high level of precision.

Younger age was associated with performing fewer SMBG. Reporting not remembering SMBG was associated with fewer SMBG and younger age. Perhaps a different lifestyle with fewer routines in young adults explains some part of this finding. Men performed fewer SMBG. We found no sex differences in reported reasons for not performing more frequent SMBG. The finding that men perform fewer SMBG is consistent with previous studies. ${ }^{6}{ }^{21}$ One explanation could be different attitudes towards exposing disease traits from a sociologic perspective. ${ }^{22}$

In this study, we also attempted to estimate how patients with type 1 diabetes perceive they should measure blood glucose. Thirty percent of patients were not aware of recommended guidelines for SMBG measurements. A total of $70 \%$ of patients were aware of guidelines but only about $40 \%$ followed them. Pain from the measurement itself has previously been described as a primary reason for why patients do not perform SMBG. $^{23}$ In the present study, we found that only $14 \%$ of patients stated this as a main reason for not performing more frequent SMBG.

Instead, we found that about $50 \%$ of patients reported not remembering and lack of time as main reasons for not performing more frequent SMBG measurements. About $20 \%$ of patients reported self-consciousness as a main reason as well. Not remembering was associated with poorer glycemic control, higher insulin doses, and fewer SMBG. Our results indicate that psychological and lifestyle factors seem to play a substantial role in performing and not performing SMBG.

Data collection in this study was completed before FGM (ie, Freestyle Libre) was available, and hence availability of CGM or CGM-like equipment was lower than it is today. Hopefully, easier and less painful methods to measure glucose will increase the proportion of patients performing recommended numbers of measurements per day. However, studies on CGM have not yet shown drastic effects on $\mathrm{HbAlc},{ }^{25}$ again emphasizing the importance of factors other than blood glucose monitoring. One problem with earlier studies on CGM and FGM is that they often focused on patients with rather good adherence to SMBG guidelines. Often, either inclusion criteria demanded adhering to SMBG $\geq 3-4$ times per $\mathrm{day}^{25-27}$ or the patient cohort had a mean SMBG measurement of $>5$ times per day. ${ }^{24}$ In the present study, this would exclude $>50 \%$ of the diabetes population in Sweden, despite the availability of free glucose meters and test strips.

Although our response rate was fairly high $(\geq 70 \%$ at 3 sites), the frequency of SMBG measurements among nonparticipating patients may have been different, which to some extent may affect the resulting frequency in the population. Sites included in this study cover nearly $100 \%$ of patients with type 1 diabetes in their defined geographical areas and include different socioeconomic groups. Thus, our study population is believed to be a representative cross section of the population in Sweden. When comparing mean age, sex, diabetes duration, and HbAlc between nationwide data in Sweden and our cohort, the composition seems similar. ${ }^{28}$ However, the fact that results may differ from those in other hospitals in Sweden due to different treatment patterns cannot be excluded, although this seems unlikely. In other countries where, for example, 
glucose strips are not available free of charge, adherence may be even lower.

In summary, this study shows that even though glucose meters and test strips are generally available at no cost in Sweden, $<50 \%$ of patients measure capillary blood glucose levels four times per day or more. This indicates a need to further support performing SMBG by increased availability and continued development of IT tools and user-friendly glucose-monitoring devices. Previous studies have shown some promising effects on adherence to SMBG recommendations through education, problem solving, contingency management, goal setting, cognitive behavioral therapy, and motivational interviewing. ${ }^{29}$ As a non-negligible proportion of patients with type 1 diabetes are not aware of SMBG guidelines, we also suggest that repeated and focused information may be essential to optimize glycemic control.

\author{
Author affiliations \\ ${ }^{1}$ Department of Internal Medicine, Alingsås Lasarett, Alingsås, Sweden \\ ${ }^{2}$ Department of Medicine, Värnamo Hospital, Värnamo, Sweden \\ ${ }^{3}$ Department of Medicine, NU Hospital Group, Uddevalla, Sweden \\ ${ }^{4}$ Department of Molecular and Clinical Medicine, Institute of Medicine, \\ Sahlgrenska Academy, University of Gothenburg, Gothenburg, Sweden \\ ${ }^{5}$ Statistiska Konsultgruppen, Gothenburg, Sweden \\ ${ }^{6}$ Department of Mathematical Sciences, Chalmers University of Technology \\ and the University of Gothenburg, Gothenburg, Sweden
}

Acknowledgements We want to thank the following persons for assistance in collecting data: Åsa Kristensson and Christina Torén, Kungälvs Sjukhus, Erik Adolfsson, research assistant, Alingsås Lasarett, Hanna Petersson Önebro, research assistant, Uddevalla Sjukhus, Marianne Wilhelmsson, Uddevalla Sjukhus, Ann Christine Nilsson, Alingsås Lasarett, and Detlef Hess, SÄS.

Contributors ML and PM designed the study and are the guarantors of this work. HI performed all statistical analysis. All authors participated in interpreting and discussing the results. PM, EA, and ML wrote a first draft of the manuscript and the supplement. All other authors reviewed and revised the manuscript.

Funding This study was supported by grants from the Region Västra Götaland, the Swedish State (ALF grant) and the Novo Nordisk Foundation.

Competing interests The author(s) declared the following potential conflicts of interest with respect to the research, authorship, and/or publication of this article: ML reports receiving honoraria or having been a consultant for AstraZeneca, Eli Lilly, Medtronic, Novo Nordisk, and Pfizer and grant support from AstraZeneca, Dexcom, Novo Nordisk, and Pfizer. All other authors declare no conflicts of interest.

Patient consent Obtained.

Ethics approval The regional ethical committee in Gothenburg, Sweden.

Provenance and peer review Not commissioned; externally peer reviewed.

Data sharing statement No additional data are available.

Open Access This is an Open Access article distributed in accordance with the Creative Commons Attribution Non Commercial (CC BY-NC 4.0) license, which permits others to distribute, remix, adapt, build upon this work noncommercially, and license their derivative works on different terms, provided the original work is properly cited and the use is non-commercial. See: http:// creativecommons.org/licenses/by-nc/4.0/

\section{REFERENCES}

1. Lind M, Svensson AM, Rosengren A. Glycemic control and excess mortality in type 1 diabetes. N Engl J Med 2015;372:880-1.
2. Ahlén E, Pivodic A, Wedel H, et al. Glycemic control, renal complications, and current smoking in relation to excess risk of mortality in persons with type 1 diabetes. J Diabetes Sci Technol 2016;10:1006-14.

3. The effect of intensive treatment of diabetes on the development and progression of long-term complications in insulin-dependent diabetes mellitus. The Diabetes Control and Complications Trial Research Group. N Engl J Med 1993;329:977-86.

4. Karter AJ, Ackerson LM, Darbinian JA, et al. Self-monitoring of blood glucose levels and glycemic control: the Northern California Kaiser Permanente Diabetes registry. Am J Med 2001;111:1-9.

5. Schütt $\mathrm{M}, \mathrm{Kern} \mathrm{W}$, Krause $\mathrm{U}$, et al. Is the frequency of self-monitoring of blood glucose related to long-term metabolic control? Multicenter analysis including 24,500 patients from 191 centers in Germany and Austria. Exp Clin Endocrinol Diabetes 2006;114:384-8.

6. Hansen MV, Pedersen-Bjergaard U, Heller SR, et al. Frequency and motives of blood glucose self-monitoring in type 1 diabetes. Diabetes Res Clin Pract 2009;85:183-8.

7. Miller KM, Beck RW, Bergenstal RM, et al. Evidence of a strong association between frequency of self-monitoring of blood glucose and hemoglobin A1c levels in T1D exchange clinic registry participants. Diabetes Care 2013;36:2009-14.

8. Evans JM, Newton RW, Ruta DA, et al. Frequency of blood glucose monitoring in relation to glycaemic control: observational study with diabetes database. BMJ 1999;319:83-6.

9. Ziegler R, Heidtmann B, Hilgard D, et al. Frequency of SMBG correlates with $\mathrm{HbA} 1 \mathrm{c}$ and acute complications in children and adolescents with type 1 diabetes. Pediatr Diabetes 2011;12:11-17.

10. American Diabetes Association. Standards of medical care in diabetes--2014. Diabetes Care 2014;37(Suppl 1):S14-80.

11. Attvall S. Egenmätning av blodglukos vid diabetes_2013.pdf [Internet]. [cited 2017 Feb 19]. Available from: http://epi.vgregion.se/ upload/L\%C3\%A4kemedel/L\%C3\%A4kemedelskommitt\%C3\%A9n/ Substans/RMR\%20Blodglukos_2013.pdf

12. Peyrot M, Rubin RR, Lauritzen T, et al. Psychosocial problems and barriers to improved diabetes management: results of the Cross-National Diabetes Attitudes, Wishes and Needs (DAWN) study. Diabet Med 2005;22:1379-85.

13. Vincze G, Barner JC, Lopez D. Factors associated with adherence to self-monitoring of blood glucose among persons with diabetes. Diabetes Educ 2004;30:112-25.

14. Thomas D, Elliott EJ. Low glycaemic index, or low glycaemic load, diets for diabetes mellitus. Cochrane Database Syst Rev 2009(1): CD006296.

15. Siebenhofer A, Plank J, Berghold A, et al. Short acting insulin analogues versus regular human insulin in patients with diabetes mellitus. Cochrane Database Syst Rev 2006(2):CD003287.

16. Baumeister H, Hutter N, Bengel J. Psychological and pharmacological interventions for depression in patients with diabetes mellitus: an abridged Cochrane review. Diabet $\mathrm{Med} \mathrm{J} \mathrm{Br}$ Diabet Assoc 2014;31:773-86.

17. Misso ML, Egberts KJ, Page M, et al. Continuous subcutaneous insulin infusion (CSII) versus multiple insulin injections for type 1 diabetes mellitus. Cochrane Database Syst Rev 2010(1):CD005103.

18. Breton MD, Kovatchev BP. Impact of blood glucose self-monitoring errors on glucose variability, risk for hypoglycemia, and average glucose control in type 1 diabetes: an in silico study. J Diabetes $\mathrm{Sci}$ Technol 2010;4:562-70.

19. Klonoff DC, Prahalad P. Performance of cleared blood glucose monitors. J Diabetes Sci Technol 2015;9:895-910.

20. Landin-Olsson M. Vägledning vid upphandling av plasmaglukosmätarsystem - pr001_vaegledning-vid-upphandling-avplasmaglukosmaetarsystem_2014-03-31.pdf [Internet]. [cited 2017 Feb 17]. Available from: http://www.equalis.se/media/93730/pr001 vaegledning-vid-upphandling-av-plasmaglukosmaetarsystem_201403-31.pdf

21. Wambui Charity K, Kumar AMV, Hinderaker SG, et al. Do diabetes mellitus patients adhere to self-monitoring of blood glucose (SMBG) and is this associated with glycemic control? Experiences from a SMBG program in western Kenya. Diabetes Res Clin Pract 2016;112:37-43.

22. Courtenay WH. Constructions of masculinity and their influence on men's well-being: a theory of gender and health. Soc Sci Med 1982 2000;50:1385-401.

23. Heinemann L. Finger pricking and pain: a never ending story. J Diabetes Sci Technol 2008;2:919-21.

24. Battelino T, Phillip M, Bratina N, et al. Effect of continuous glucose monitoring on hypoglycemia in type 1 diabetes. Diabetes Care 2011;34:795-800. 
25. Bergenstal RM, Tamborlane WV, Ahmann A, et al. Effectiveness of sensor-augmented insulin-pump therapy in type 1 diabetes. N Engl J Med 2010;363:311-20.

26. Conget I, Battelino T, Giménez M, et al. The SWITCH study (sensing with insulin pump therapy to control $\mathrm{HbA}(1 \mathrm{c})$ ): design and methods of a randomized controlled crossover trial on sensor-augmented insulin pump efficacy in type 1 diabetes suboptimally controlled with pump therapy. Diabetes Technol Ther 2011;13:49-54.
27. An Evaluation of Novel Glucose Sensing Technology on Hypoglycaemia in Type 1 Diabetes (IMPACT) - Tabular ViewClinicalTrials.gov [Internet]. (cited 2016 Mar 14). https://clinicaltrials. gov/ct2/show/record/NCT02232698.

28. Guðbbjörnsdóttir S. Arsrapport_NDR_2014.pdf [Internet]. [cited 2017 Feb 19]. Available from: https://www.ndr.nu/pdfs/Arsrapport_NDR_2014.pdf

29. Patton SR. Adherence to glycemic monitoring in diabetes. J Diabetes Sci Technol 2015;9:668-75. 